\title{
Dose-Related Enhancement of Mood and Cognition in Smokers Administered Nicotine Nasal Spray
}

\author{
Carol S Myers*,', Richard C Taylor', Eric T Moolchan' and Stephen J Heishman' \\ 'Clinical Pharmacology and Therapeutics Branch, National Institute on Drug Abuse, NIH Intramural Research Program, Baltimore, MD, USA
}

\begin{abstract}
The discovery of the role of nicotinic receptors in attention and memory has led to the testing of nicotinic analogs as cognitive enhancing agents in patient populations. Empirical information about nicotine's ability to enhance elements of attention and memory in normal individuals might guide development of therapeutic uses of nicotine in cognitively impaired populations. The purpose of this study was to determine the effect of nicotine on continuous attention, working memory, and computational processing in tobacco-deprived and nondeprived smokers. A total of 28 smokers ( 14 men, 14 women) participated in a double-blind, placebo-controlled, within-subject study, in which they were overnight $(12 \mathrm{~h}$ ) tobacco deprived at one session and smoked ad libitum before the other session. At each session, participants received 0,1 , and $2 \mathrm{mg}$ nicotine via nasal spray in random order at 90 min intervals. Before and after each dose, a battery of cognitive, subjective, and physiological measures was administered, and blood samples were taken for plasma nicotine concentration. Overnight tobacco deprivation resulted in impaired functioning on all cognitive tests and increased self-reports of tobacco craving and negative mood; nicotine normalized these deficits. In the nondeprived condition, nicotine enhanced performance on the continuous performance test (CPT) and an arithmetic test in a dose-related manner, but had no effect on working memory. In general, women were more sensitive than men to the subjective effects of nicotine. These results provide an unequivocal determination that nicotine enhanced attentional and computational abilities in nondeprived smokers and suggest these cognitive domains as substrates for novel therapeutic indications.
\end{abstract}

Neuropsychopharmacology (2008) 33, 588-598; doi:I0.I038/sj.npp. I30 I425; published online I8 April 2007

Keywords: nicotine nasal spray; performance; sustained attention; information processing; working memory; plasma nicotine

\section{INTRODUCTION}

Although the majority of cigarette smokers express a desire to quit smoking, less than $10 \%$ of those who try to quit remain tobacco abstinent after 1 year (National Cancer Institute, 2003). A significant impediment to quitting for most smokers is the nicotine withdrawal syndrome. In addition to the mood and physiological changes typically observed during nicotine withdrawal, abstinent smokers frequently report difficulty concentrating (American Psychiatric Association, 2000). Studies have documented withdrawal-induced cognitive impairment and the ability of nicotine to reverse such deficits (for reviews, see Heishman et al, 1994; Sherwood, 1993). Studies have also shown that nicotine can enhance certain aspects of attention and memory in the absence of withdrawal (Heishman, 1998).

The beneficial effects of nicotine on human cognition are corroborated by the preclinical literature. Animal studies

*Correspondence: Dr CS Myers, Nicotine Psychopharmacology Unit, NIDA Intramural Research Program, 5500 Nathan Shock Drive, Baltimore, MD 21224, USA, Tel: + I 410550 3149, Fax: + | 410550 1528, E-mail: cmyers@intra.nida.nih.gov

Received 24 October 2006; revised 6 March 2007; accepted 19 March 2007 have demonstrated that acute and chronic nicotine administration facilitates visual signal detection (Rezvani et al, 2004; Bizarro et al, 2004), spatial working memory (Levin et al, 1997; Bancroft and Levin, 2000), spatial learning (Socci et al, 1995), and delayed match-to-sample task (Buccafusco and Jackson, 1991). The mechanisms by which nicotine enhances cognitive performance are not fully understood. Nicotine, via binding to presynaptic nicotinic cholinergic receptors, facilitates the release of various neurotransmitters, including dopamine, norepinephrine, serotonin, glutamate, and acetylcholine, all of which have been implicated in cognitive functioning (Levin et al, 2006; Wonnacott, 1997). However, two nicotinic receptor subtypes, $\alpha 4 \beta 2$ and $\alpha 7$, have been shown to be involved in learning and memory. The $\alpha 4 \beta 2$ agonists, RJR 2403 and SIB 1765F, improved working memory (Levin and Christopher, 2002) and signal detection in a choice reaction test (Grottick and Higgins, 2000), respectively. The $\alpha 7$ nicotinic receptor is expressed in high concentration in the hippocampus. The $\alpha 7$ agonist, ARR 17779, enhanced working memory (Levin et al, 1999) and social recognition (Van Kampen et al, 2004) in rodent models. Further, infusion into the hippocampus of dihydro- $\beta$-erythroidine, a selective $\alpha 4 \beta 2$ antagonist, and methyllycaconitine, a selective $\alpha 7$ antagonist, produced working memory impairments (Felix and Levin, 1997). 
The discovery of the role of nicotinic receptors in attention and memory has led to the testing of nicotine and nicotine analogs as potential cognitive enhancing agents in patient populations with cognitive deficits (Levin et al, 2006). For example, nicotine transiently attenuated some of the attentional and cognitive deficits seen in the elderly (Min et al, 2001); Down's syndrome individuals (Seidl et al, 2000); and patients with Alzheimer's disease (White and Levin, 1999), Parkinson's disease (Kelton et al, 2000), schizophrenia (Myers et al, 2004), and attention deficit/hyperactivity disorder (Conners et al, 1996). Empirical information about nicotine's ability to enhance elements of attention and memory in cognitively intact individuals might guide development of novel therapeutic uses of nicotine in cognitively impaired populations.

Two extensive reviews on the effects of nicotine and smoking on human performance indicated that the majority of studies were conducted with tobacco-deprived smokers, thus documenting withdrawal relief rather than enhancement, and that the preponderant measure of performance was attention (Heishman et al, 1994; Sherwood, 1993). Heishman et al (1994) also noted several methodological deficiencies in the majority of studies, including small sample size ( $n \leqslant 20$ in $58 \%$ of studies), lack of placebo control and double-blind drug administration (74\% of experiments), imprecise nicotine dosing via ad libitum cigarette smoking (70\% of studies), lack of plasma concentration data to indicate delivered dose of nicotine (99\% of studies), testing only smokers who were tobacco deprived for more than $8 \mathrm{~h}$ (60\% of experiments), and lack of testing multiple nicotine doses (89\% of studies).

In this study, we addressed these issues by administering placebo and active nicotine via a metered nasal spray. Measures included plasma nicotine concentration, subjective ratings of drug effects, and tests of three cognitive domains: continuous attention, working memory, and computation. Studies have shown that nicotine or smoking enhanced sustained attention by attenuating the vigilance decrement that typically occurred during lengthy signal detection tasks (Heishman et al, 1994) and in briefer tests of continuous attention (Lawrence et al, 2002; Trimmel and Wittberger, 2004). We included a test of continuous attention in this study as a positive control. In contrast, the effect of nicotine on working memory and computational skills is less clear. Some studies reported enhanced working memory following nicotine administration to nonsmokers (Foulds et al, 1996; Kumari et al, 2003; McClernon et al, 2003) and former smokers and abstinent smokers (Ernst et al, 2001). In contrast, other studies reported that nicotine either had no effect (Heishman et al, 1993; Kleykamp et al, 2005; Myers et al, 2004) or impaired working memory (Park et al, 2000). Heishman and Henningfield (2000) found that nicotine gum enhanced speed, but decreased working memory accuracy in nonsmokers. The few studies examining the effect of nicotine on mental arithmetic or computational skills also reported inconsistent findings. Landers et al (1992) found that smokeless tobacco increased correctly answered problems compared with nonusers, but the improvement was not dose related. Two studies reported that nicotine gum had no effect on mental arithmetic in nonsmokers (Heishman et al, 1993; Heishman and Henningfield, 2000). Thus, we included in this study tests of working memory and computational skills to bring clarity to these cognitive domains.

We administered nicotine $(0,1$, and $2 \mathrm{mg})$ to tobaccodeprived and nondeprived smokers and tested the following hypotheses: (1) overnight $(12 \mathrm{~h})$ tobacco deprivation would impair performance in tests of continuous attention, working memory, and mental arithmetic, (2) nicotine would reverse these cognitive deficits in a dose-related manner, (3) nicotine would enhance cognitive performance in nondeprived smokers, and (4) nicotine would produce dose-related changes in drug effect ratings and physiological measures.

\section{MATERIALS AND METHODS}

\section{Participants}

Twenty-eight cigarette smokers (14 men, 14 women) were recruited via newspaper, radio, and television advertisements (Table 1). Inclusionary criteria were $18-50$ years old, having smoked a minimum of 15 cigarettes per day for at least 1 year, and no current interest in reducing or quitting smoking. The sample consisted of 12 African Americans (5 men, 7 women) and 16 Caucasians ( 9 men, 7 women). Before the study, subjects were given thorough medical and psychiatric examinations and were interviewed about history of drug use. With respect to drug use during the past 30 days, $57 \%$ of participants reported drinking alcohol, one reported using cocaine once, and one reported using marijuana on 12 occasions. Participants gave written informed consent according to guidelines for the protection of human research volunteers of the US Department of Health and Human Services and were paid for their participation. The National Institute on Drug Abuse Institutional Review Board approved the study.

\section{Nicotine Administration}

Nicotine was administered in the form of the marketed nasal spray, Nicotrol (Pfizer). Each actuation of Nicotrol delivers a metered $50 \mu \mathrm{l}$ spray containing approximately $0.5 \mathrm{mg}$ nicotine. A placebo spray was prepared by adding $5 \mu \mathrm{l}$ of $3 \%$ capsaicin solution to $20 \mathrm{ml}$ sterile saline. The placebo solution was placed in empty, clean Nicotrol bottles to allow double-blind administration.

Table I Relevant Characteristics of Participants (mean \pm SD)

\begin{tabular}{lccc}
\hline Characteristic & Women & Men & Total \\
\hline Age (years) & $36.5 \pm 9.0$ & $36.0 \pm 8.9$ & $36.0 \pm 8.8$ \\
Education (years) & $12.4 \pm 2.4$ & $12.9 \pm 1.9$ & $12.6 \pm 2.2$ \\
Estimated IQ $^{\mathrm{a}}$ & $99.1 \pm 12.4$ & $99.9 \pm 12.5$ & $100 \pm 12$ \\
Years smoking $_{\text {Cigarettes per day }}$ & $17.7 \pm 8.5$ & $16.9 \pm 9.6$ & $17.3 \pm 8.9$ \\
Nicotine dependence $^{\mathrm{b}}$ & $22.7 \pm 7.1$ & $21.8 \pm 7.0$ & $22.3 \pm 6.9$ \\
\hline
\end{tabular}

Abbreviation: $I Q$, intelligence quotient.

aShipley Institute on Living Scale (Shipley, 1946).

bFagerstrom test for nicotine dependence (Heatherton et al, 199I). 


\section{Procedure}

Subjects participated in an orientation session and two experimental sessions. During the orientation session, they practiced the cognitive tests, reviewed the subjective questionnaires, and were administered the highest dose of nicotine $(2 \mathrm{mg})$ to screen for significant adverse effects. Participants were instructed to perform the cognitive tests as rapidly and accurately as possible. The two experimental sessions were scheduled at least $48 \mathrm{~h}$ apart. Before one session, participants were overnight $(12 \mathrm{~h})$ tobacco deprived as verified by expired air carbon monoxide $(\mathrm{CO}) \leqslant 10$ parts per million (p.p.m.). They arrived for the other session having smoked ad libitum and smoked one preferred-brand cigarette $30 \mathrm{~min}$ before the session began to standardize the time since last tobacco exposure. Order of the experimental sessions was counterbalanced. Participants were required to abstain from alcohol and other drugs (except caffeine and prescription drugs) $24 \mathrm{~h}$ before each session. Compliance was assessed by a brief neuromotor exam (Heishman et al, 1996) and a breathalyzer test.

At each experimental session, participants were administered three doses of nicotine at 90 min intervals. Dose order was randomized using a Latin square, and each participant received the same order at both sessions. Doses of nicotine were 0 (four sprays of placebo), 1 (two sprays of Nicotrol and two sprays of placebo), and $2 \mathrm{mg}$ (four sprays of Nicotrol). The dosing protocol was one spray per nostril followed $2 \mathrm{~min}$ later by the second two sprays. Before and after each dose, a battery of cognitive, subjective, and physiological measures was administered as shown in Table 2.

\section{Cognitive Measures}

Continuous performance test (CPT). Continuous attention was measured using a $6 \mathrm{~min}$ CPT (Sunrise Systems, Pembroke, MA). Participants monitored letters that were displayed individually on a screen in rapid succession and pressed a button only when the letter $X$ (target) appeared. Each letter stimulus (total of 500, 100 targets) was presented for $100 \mathrm{~ms}$, with a $600 \mathrm{~ms}$ interstimulus interval. Measures included percent correct target responses (hits), percent nontarget responses (false alarms), adjusted percent correct responses (hits minus false alarms to correct for random responding), mean response time, and mean response time variability. Because this version of the CPT is relatively easy, we used a degraded version, in which $30 \%$ of the pixels of each letter were absent. This produced a blurred visual stimulus, resulting in approximately $85 \%$ hits and $25 \%$ false alarms, based on pilot data.

Arithmetic test. Computational skills and information processing speed were assessed with an arithmetic test developed by the authors. Fifty single-digit addition or subtraction problems with a solution appeared individually on the computer monitor; half of the problems were solved correctly and half incorrectly. Each problem remained on the monitor until participants pressed a key indicating whether the solution was correct or incorrect. Percent correct responding and mean response time were recorded.

$N$-back test. Working memory was examined with the 6 min $\mathrm{N}$-back test. Participants were required to hold in memory a
Table 2 Timeline and Measures for Each Dose of Nicotine

\begin{tabular}{ll}
\hline Time (min) & Assessment \\
\hline-20 & BP, HR, blood sample \\
-18 & Continuous performance test \\
-13 & N-back test \\
-8 & Arithmetic test \\
-5 & VAS items \\
-4 & TCQ \\
0 & Nicotine dosing \\
5 & VAS items \\
6 & BP, HR, blood sample \\
8 & VAS items \\
9 & N-back test \\
14 & BP, HR, blood sample \\
16 & Continuous performance test \\
21 & BP, HR, blood sample \\
23 & VAS items \\
24 & TCQ \\
25 & Arithmetic test \\
40 & BP, blood sample \\
\hline & \\
\hline & \\
\hline &
\end{tabular}

Abbreviations: $\mathrm{BP}$, blood pressure; HR, heart rate; $\mathrm{TCQ}$, tobacco craving questionnaire; VAS, visual analog scale.

series of letters that were presented individually on a computer monitor for $500 \mathrm{~ms}$, with an interstimulus interval of $2500 \mathrm{~ms}$. We used a 2-back version of the test (Cohen et al, 1994), in which participants pressed a key when a letter was repeated with one intervening letter (ie matched a letter two back in the series). Percent correct responding and mean response time were recorded.

\section{Subjective Measures}

Visual analog scale (VAS). The following VAS items were used to assess the effects of the nasal spray: relaxed, alert, jittery, urge to smoke, head rush, drowsy, pleasant, liking of drug, uneasy, stimulated, positive mood, and negative mood. Participants responded to each item by placing a vertical mark along a $100 \mathrm{~mm}$ line labeled 'not at all' on the left and 'extremely' on the right.

Tobacco craving questionnaire (TCQ; Heishman et al, 2003). Factor analysis of the 47-item TCQ resulted in four factors. In this study, we used a 12-item version of the TCQ, comprising the three items from each factor that exhibited optimal within-factor reliability (Cronbach's coefficient $\alpha$ ) and inter-item correlation. Factor scale scores for each participant were obtained by summing the three items in each factor. A total craving score was obtained by summing the 12 items.

\section{Plasma and Physiological Measures}

Before each of the two experimental sessions, a venous catheter was inserted in the nondominant forearm. Blood samples $(5 \mathrm{ml})$ were drawn into ethylenediaminetetraacetic acid-containing tubes at several time points (see Table 2) and 
immediately placed on ice. Samples were centrifuged and plasma stored at $-80^{\circ} \mathrm{C}$. Plasma samples were assayed for nicotine and cotinine (Labstat International, Kitchener, ON). Expired air $\mathrm{CO}$ was measured using a handheld breath monitor (Vitalograph, Lenexa, KS). Systolic and diastolic blood pressure and heart rate were measured using an automated vital signs monitor (Datascope Corp., Paramus, NJ).

\section{Data Analysis}

Participant demographic and smoking history variables were analyzed for sex differences using independent group $t$-tests. To examine the effect of tobacco deprivation, a twoway analysis of variance (ANOVA) was conducted using the initial baseline data of each session for the three cognitive tests, VAS items, TCQ, expired air CO, vital signs, and plasma nicotine and cotinine. Sex was the between-subjects factor, and tobacco condition (deprived, nondeprived) was the within-subjects factor.

For the primary analysis, data from the cognitive tests, VAS items, TCQ, vital signs, and plasma nicotine and cotinine were expressed as change scores using baseline data obtained before each dose. Cognitive and TCQ data were analyzed using a three-way repeated measures ANOVA with nicotine dose $(0,1$, and $2 \mathrm{mg})$, tobacco condition, and sex as the factors. Data from the VAS items, vital signs, and plasma nicotine and cotinine were analyzed using a fourway repeated measures ANOVA with dose, condition, sex, and time postdose (see Table 2) as factors. ANOVAs were conducted using the mixed models procedure in SPSS. For data sets that failed Mauchly's test of sphericity (CO, heart rate, blood pressure, TCQ factor 1), Huynh-Feldt probability levels were used to interpret ANOVA results, and the corrected F values are reported. Post hoc comparisons between means were conducted using Fisher's least significant difference test. Correlations between maximal plasma nicotine concentration $\left(C_{\max }\right)$ and cognitive performance were conducted using Pearson's product-moment correlation. All statistical tests were two-tailed, and results were considered significant at $p<0.05$.

\section{RESULTS}

\section{Participants}

Relevant sample characteristics are shown in Table 1; no sex differences were observed for any variable. All participants were able to tolerate the active nicotine doses at each session, although most experienced a burning sensation in the nose and throat accompanied by watery eyes, and two reported stomach discomfort. These side effects remitted within 2-3 min.

\section{Tobacco Deprivation Effects}

Compared with the nondeprived condition, overnight tobacco deprivation decreased expired air CO (mean \pm SE, $8.8 \pm 2.7$ vs $28.6 \pm 10.4$ p.p.m., $p<0.001$ ), heart rate $(69.1 \pm 1.7$ vs $79.8 \pm 1.6$ beats per min, $p<0.001)$, plasma nicotine concentration $(2.9 \pm 0.2$ vs $10.4 \pm 1.4 \mathrm{ng} / \mathrm{ml}$, $p<0.001)$, and plasma cotinine concentration $(184.2 \pm 16.9$ vs $255.8 \pm 19.5 \mathrm{ng} / \mathrm{ml}, p<0.01)$. There was a significantly lower $(p<0.01)$ baseline cotinine concentration in women than men in both deprived (women $134.2 \pm 20.6 \mathrm{ng} / \mathrm{ml}$, men $230.5 \pm 19.9 \mathrm{ng} / \mathrm{ml}$ ) and nondeprived (women 223.8 \pm $27.2 \mathrm{ng} / \mathrm{ml}$, men $285.4 \pm 26.2 \mathrm{ng} / \mathrm{ml}$ ) conditions. Tobacco deprivation increased ratings on VAS items, urge to smoke $(70.9 \pm 5.0$ vs $48.6 \pm 5.3, p<0.01)$ and negative mood (28.6 \pm 4.1 vs $16.3 \pm 3.7, p=0.05)$, and total TCQ score $(51.4 \pm 3.0 v s$ $39.6 \pm 3.5, p<0.01)$. A decreased trend following deprivation was observed for VAS ratings of relaxed $(p=0.08)$ and alert $(p=0.09)$. Deprivation also resulted in impaired performance compared with nondeprivation on the following measures: CPT correct responses $(73.1 \pm 4.2$ vs $79.1 \pm$ 3.7, $p<0.01)$, CPT adjusted correct responses $(15.4 \pm 6.0 v \mathrm{~s}$ $29.4 \pm 6.8, p<0.01)$, CPT response time variability $(217.2 \pm$ $18.8 v s 188.1 \pm 18.0, p<0.05)$, N-back accuracy $(76.7 \pm 3.2 v s$ $84.2 \pm 2.7, p<0.01)$, and arithmetic response time $(2243.8 \pm$ 108.2 vs $2048.6 \pm 102.9 \mathrm{~ms}, p<0.05)$.

\section{Nicotine Effects}

\section{Cognitive measures.}

CPT: Data from three participants were lost due to computer error. Under conditions of tobacco deprivation and nondeprivation, nicotine increased percent correct responding $\left(\mathrm{F}_{2,46}=5.29, p=0.009\right)$, increased adjusted percent correct responding $\left(\mathrm{F}_{2,46}=6.83, p=0.003\right)$, and decreased response time variability $\left(\mathrm{F}_{2,46}=3.71, p=0.03\right)$. For all three measures, post hoc tests indicated that the $2 \mathrm{mg}$ dose was significantly different from placebo $(p<0.05)$. The effect of nicotine to decrease response time was most evident in men in the deprived condition, resulting in a significant three-way interaction between dose, condition, and sex $\left(F_{2,46}=5.47, p=0.007\right)$. The three-way interaction was also significant for false alarms, such that reliable decreases were shown by women in the deprived condition and by men in the nondeprived condition $\left(\mathrm{F}_{2,46}=4.60\right.$, $p=0.015)$. Figure 1 shows results of post hoc comparisons between means of selected CPT measures. In general, significant changes from placebo were observed only with $2 \mathrm{mg}$ nicotine.

Arithmetic: In both tobacco-deprived and nondeprived conditions, nicotine enhanced percent correct responding $\left(\mathrm{F}_{2,52}=6.98, p=0.001\right)$ and decreased mean response time $\left(\mathrm{F}_{2,52}=5.83, p=0.004\right)$. Post hoc tests indicated that the 1 and $2 \mathrm{mg}$ doses were significantly different from placebo for correct responding $(p<0.01)$ and response time $(p<0.05)$. Figure 2 shows that correct responding was very similar for men in both conditions and women in the deprived condition, with significant improvement at $2 \mathrm{mg}$ nicotine compared with placebo. In contrast, women during the nondeprived session showed increased accuracy only after $1 \mathrm{mg}$ nicotine, resulting in a significant two-way interaction between dose and $\operatorname{sex}\left(\mathrm{F}_{2,52}=3.15, p=0.047\right)$.

N-back: Nicotine did not produce significant effects on accuracy or response time on working memory.

\section{Subjective measures.}

VAS: Nicotine produced differential effects as a function of condition and sex on most subjective measures. Of the 12 VAS items, 7 showed significant nicotine effects, which were 

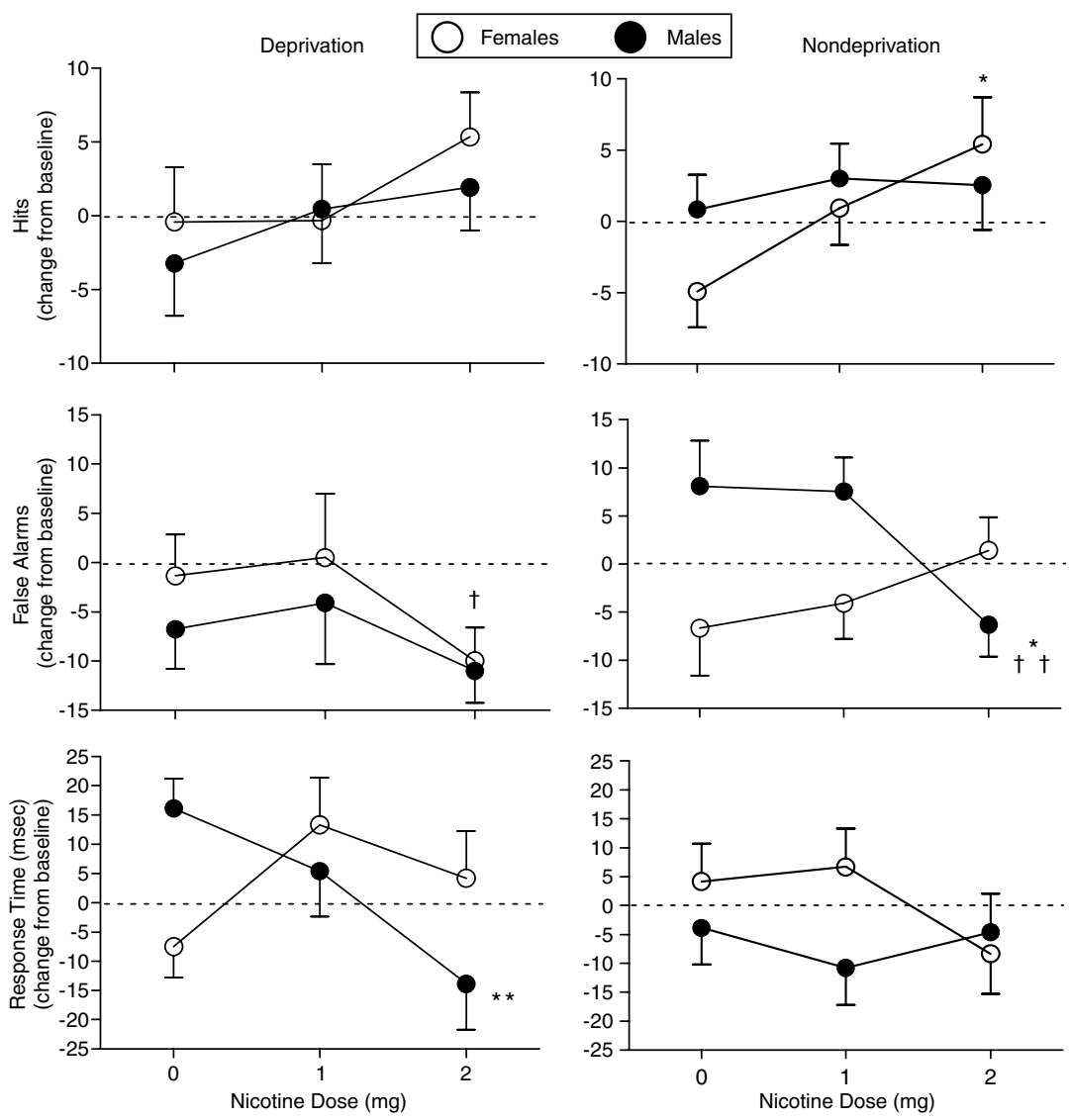

Figure I Effect of nicotine under conditions of tobacco deprivation and nondeprivation on hits (top row), false alarms (middle row), and response time (bottom row) on the CPT. Each data point represents the mean $( \pm$ SE) change from baseline score of men $(n=13)$ or women $(n=12)$. Significant threeway (dose $\times$ condition $\times$ sex) post hoc comparisons are as follows: ${ }^{*} p<0.05$ different from $0 \mathrm{mg}$ dose, ${ }^{*} * 0<0.0$ l different from $0 \mathrm{mg}$ dose, ${ }^{\dagger} p<0.05$ different from I mg dose, ${ }^{\dagger \dagger} p<0.0$ I different from I mg dose.

characterized by either two-way (dose $x$ sex or dose $\times$ condition) or three-way (dose, condition, and sex) interactions. Nicotine had no significant effect on ratings of relaxed, alert, head rush, and drowsy. There was no difference between placebo and active nicotine in ratings of drug liking, suggesting that the placebo spray effectively mimicked the nasal irritation of active nicotine. Mean \pm SE drug liking ratings were $21.2 \pm 4.0,21.1 \pm 4.1$, and $25.4 \pm 3.9$ for 0,1 , and $2 \mathrm{mg}$ nicotine, respectively.

Figure 3 shows data for the seven significant VAS items averaged over the postdose assessments. For most measures, ratings peaked at $5 \mathrm{~min}$ postdose and declined to baseline over each dosing trial. Ratings of positive mood showed a sex main effect $\left(\mathrm{F}_{1,26}=12.64, p<0.001\right)$ and a dose $\times$ condition interaction $\left(\mathrm{F}_{2,52}=3.86, p=0.02\right)$ such that nicotine increased ratings of positive mood in women in the tobacco-deprived condition, but had no effect in men (Figure 3). Nicotine (1 mg) decreased positive mood in both sexes in the nondeprived condition, which was significant for women $(p<0.05)$. Interactions of dose $\times$ sex $\left(\mathrm{F}_{2,52}=5.58, p=0.004\right)$ and condition $\times \operatorname{sex}\left(\mathrm{F}_{2,52}=6.36\right.$, $p=0.012$ ) were observed for ratings of pleasant. Nicotine $(2 \mathrm{mg})$ decreased ratings of pleasant in men in the deprived condition $(p<0.01)$, whereas $1 \mathrm{mg}$ nicotine decreased ratings in women during nondeprivation $(p=0.05)$. In contrast, nicotine $(2 \mathrm{mg}$ ) increased ratings of stimulated in both sexes in the nondeprived, but not deprived, condition $\left(\mathrm{F}_{2,52}=3.23, p=0.04\right)$.

Nicotine decreased urge to smoke in women in the nondeprived condition, but had no effect in men, as shown by a dose $\times$ sex interaction $\left(\mathrm{F}_{2,52}=6.27, p=0.002\right)$. Nicotine decreased negative mood in women in both conditions and increased negative mood in men in the nondeprived session, as evidenced by interactions of dose $\times$ sex $\left(\mathrm{F}_{2,52}=13.89, p<0.001\right)$ and dose $\times$ condition $\left(\mathrm{F}_{2,52}=4.61\right.$, $p=0.01)$. Nicotine reliably decreased ratings of uneasy in women in the deprived condition $(p<0.01)$, but had no effect in men, resulting in a three-way interaction between dose, condition, and sex $\left(\mathrm{F}_{2,52}=4.03, p=0.018\right)$. The same three-way interaction was significant for ratings of jittery, such that $2 \mathrm{mg}$ nicotine decreased ratings in men in the deprived condition and in women in the nondeprived condition $\left(\mathrm{F}_{2,52}=6.41, p=0.002\right)$.

TCQ: The interaction between dose and sex was significant for the total TCQ score $\left(\mathrm{F}_{2,52}=3.22, p=0.045\right)$. Figure 4 illustrates this interaction; women, but not men, reported significantly less craving after $2 \mathrm{mg}$ nicotine $(p<0.01)$. There was no difference as a function of condition, even though total TCQ score at baseline was 


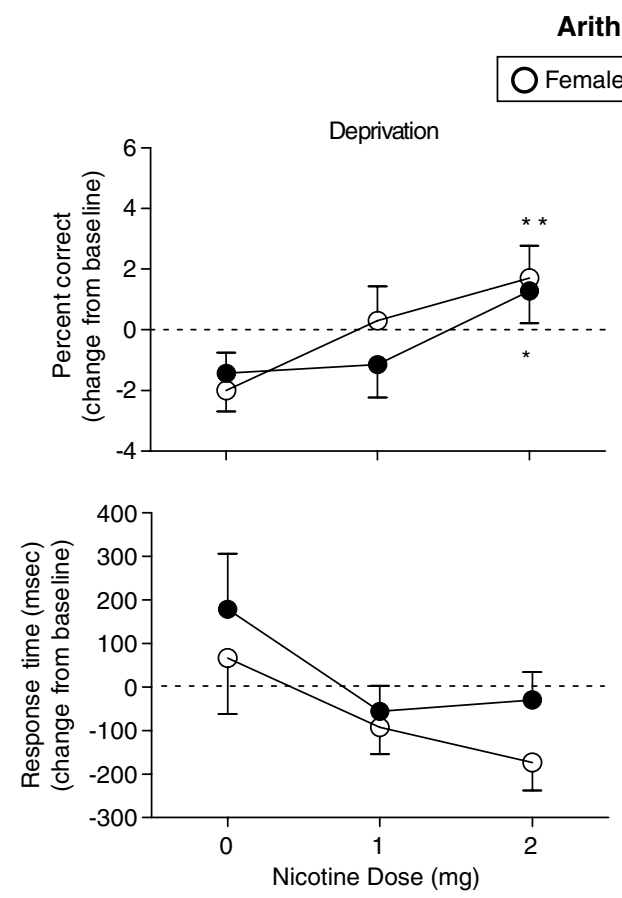

Arithmetic Test
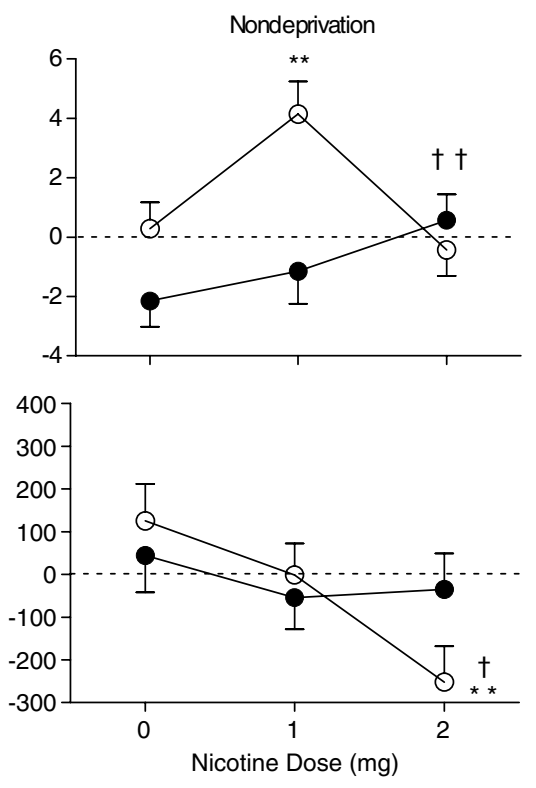

Figure 2 Effect of nicotine under conditions of tobacco deprivation and nondeprivation on percent correct responses (top row) and response time (bottom row) on the arithmetic test. Each data point represents the mean $( \pm$ SE) change from baseline score of men $(n=14)$ or women $(n=\mid 4)$. Significant three-way (dose $\times$ condition $\times$ sex) post hoc comparisons are as follows: $* p<0.05$ different from 0 mg dose, $* * p<0.0$ l different from 0 mg dose, ${ }^{\dagger} p<0.05$ different from I mg dose, ${ }^{\dagger \dagger} p<0.0$ I different from I mg dose.

greater in the deprived condition compared with nondeprivation (see above). A dose $\times$ sex interaction was also observed for the individual factors emotionality $\left(\mathrm{F}_{2,52}=4.32, p=0.016\right)$ and purposefulness $\left(\mathrm{F}_{2,52}=4.33\right.$, $p=0.016)$ with women, but not men, exhibiting a significant decrease in TCQ scores after $2 \mathrm{mg}$ nicotine. Although not significant, a similar interactive response pattern was seen for the expectancy and compulsivity factors.

Physiological measures. Figure 5 shows heart rate and blood pressure measurements recorded at $6 \mathrm{~min}$ postdose, which was the time of maximal nicotine effect. For both measures, effects declined to baseline over each $40 \mathrm{~min}$ dosing trial (time main effect, $p<0.05$ for all measures). Nicotine increased heart rate as evidenced by a dose main effect $\left(\mathrm{F}_{2,52}=6.56, p=0.002\right)$ and a dose $\times$ sex interaction $\left(\mathrm{F}_{2,52}=5.43, p=0.005\right)$. Men showed reliable increases after both active nicotine doses in the deprived condition $(p<0.05)$, whereas women increased only after the $2 \mathrm{mg}$ dose $(p<0.01)$. Heart rate increases were significantly greater in the tobacco-deprived than nondeprived condition $\left(\mathrm{F}_{1,26}=25.21, p<0.001\right)$ primarily because of lower baseline heart rate in the deprived condition. There was a significant three-way interaction between dose, condition, and sex for systolic blood pressure $\left(\mathrm{F}_{2,52}=6.15, p=0.002\right)$ and diastolic blood pressure $\left(\mathrm{F}_{2,52}=5.37, p=0.005\right)$ (Figure 5). Women showed reliable blood pressure increases after active nicotine in the nondeprived, but not deprived, condition, except for systolic pressure after $2 \mathrm{mg}$ nicotine. In contrast, men showed significant increases in diastolic pressure only after the $2 \mathrm{mg}$ dose in the deprived $(p<0.05)$ and nondeprived $(p<0.01)$ conditions.
Plasma drug concentration. Plasma samples were not obtained from one participant. Significant main effects of dose $\left(F_{2,50}=31.57, p<0.001\right)$, time $\left(F_{3,75}=5.22, p=0.002\right)$, and a dose $\times$ condition interaction $\left(\mathrm{F}_{2,50}=7.36, p=.001\right)$ were observed. Post hoc tests indicated that both active nicotine doses were significantly different from placebo and each other $(p<0.05)$ in the tobacco-deprived condition, whereas only the $2 \mathrm{mg}$ dose was significantly increased over placebo $(p<0.001)$ in the nondeprived condition. $C_{\max }$ was 4.8 and $5.4 \mathrm{ng} / \mathrm{ml}$ in the deprived condition and 9.5 and $13.6 \mathrm{ng} / \mathrm{ml}$ in the nondeprived condition for the 1 and $2 \mathrm{mg}$ doses, respectively. Figure 6 shows that the $2 \mathrm{mg}$ dose produced a peak increase over baseline of $5 \mathrm{ng} / \mathrm{ml}$ at $6 \mathrm{~min}$ postdose in the nondeprived condition, which declined over $40 \mathrm{~min}$ to predose baseline. In contrast, smaller increases were observed after 1 and $2 \mathrm{mg}$ nicotine in the tobaccodeprived condition, which peaked at $14 \mathrm{~min}$ postdose. Unlike the deprived condition, plasma concentration declined below predose baseline after the 0 and $1 \mathrm{mg}$ doses in the nondeprived condition. Plasma cotinine concentration was relatively stable, exhibiting small $(5-7 \mathrm{ng} / \mathrm{ml})$, but significant, increases at 6-14 min postdose as a function of nicotine dose $\left(\mathrm{F}_{2,50}=7.07, p=0.001\right)$.

Several measures of the CPT were correlated with nicotine. Adjusted percent correct responding was correlated with $2 \mathrm{mg}$ nicotine $C_{\max }$ in the tobacco-deprived condition $(r=0.47, p=0.022)$. Significant correlations were also observed between $2 \mathrm{mg}$ nicotine $C_{\max }$ and false alarms in the deprived $(r=-0.46, p=0.023)$ and nondeprived $(r=0.50, p=0.013)$ conditions and variability of response time in the deprived condition $(r=-0.50, p=0.014)$. Response time in the arithmetic test was correlated with 

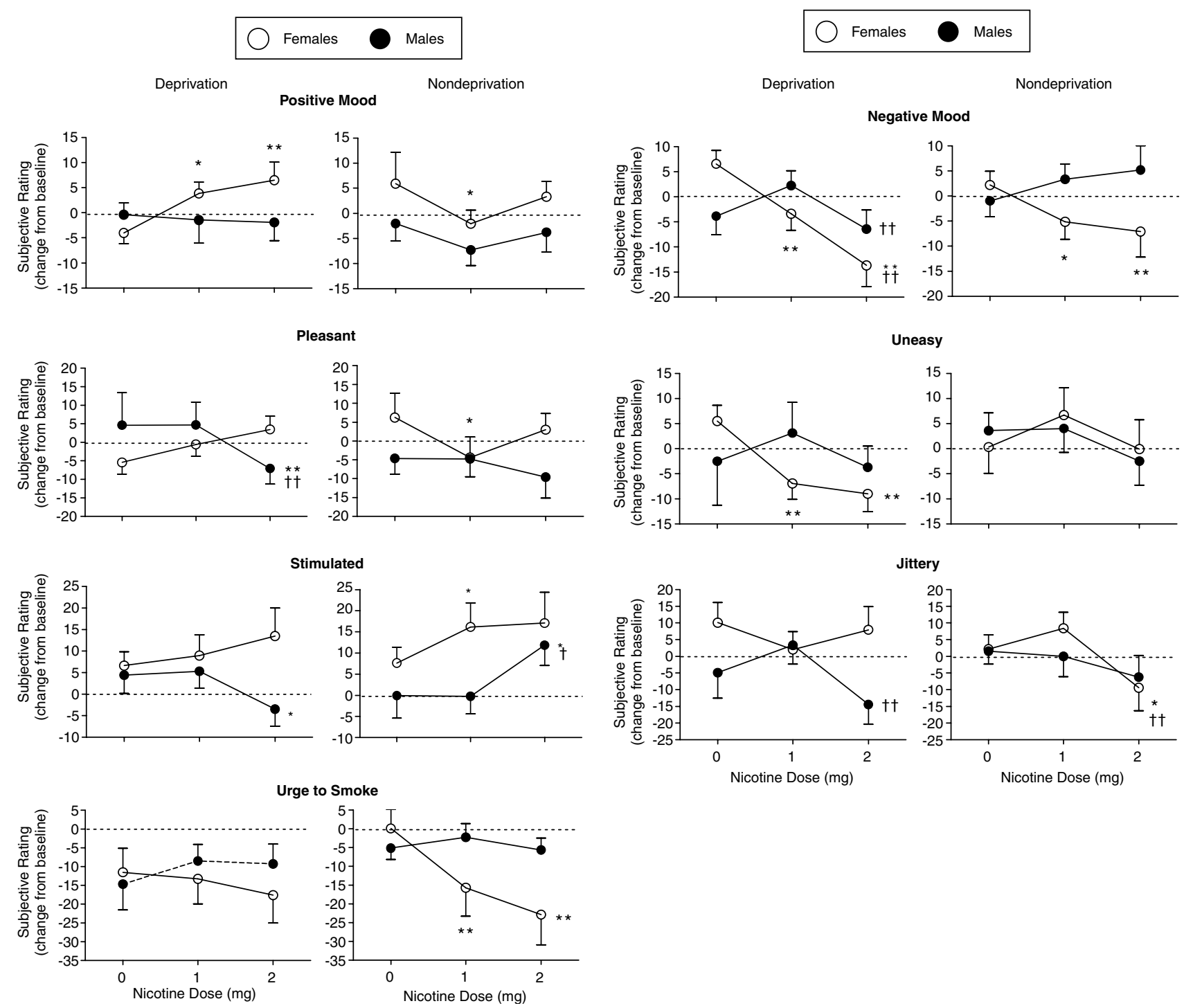

Figure 3 Effect of nicotine under conditions of tobacco deprivation and nondeprivation on VAS items showing a significant nicotine effect. Each data point represents the mean $( \pm$ SE) change from baseline score of men $(n=14)$ or women $(n=14)$ averaged over the three postdose measurements. Significant three-way (dose $\times$ condition $\times$ sex) post hoc comparisons are as follows: $* p<0.05$ different from 0 mg dose, $* * p<0.0$ l different from 0 mg dose, ${ }^{\dagger} p<0.05$ different from I mg dose, ${ }^{\dagger \dagger} p<0.01$ different from I mg dose.

$1 \mathrm{mg}$ nicotine $C_{\max }$ in the deprived condition $(r=0.38$, $p=0.05)$.

\section{DISCUSSION}

The primary purpose of this study was to examine the doseresponse function of nicotine on elements of cognitive processing. Nicotine increased correct responding and decreased response time measures on tests of continuous attention and computational processing, but had no effect on working memory. As expected, $12 \mathrm{~h}$ of tobacco deprivation resulted in impaired functioning on all cognitive tests and increased self-reports of tobacco craving and negative mood, indicative of early nicotine withdrawal. Nicotine normalized deficits in cognitive performance and mood following tobacco deprivation. More importantly, in the nondeprived condition, nicotine produced modest enhance- ment of attentional and computational performance beyond baseline. This issue of primary enhancement $v s$ withdrawal relief has been central to the debate on the performance effects of nicotine (Heishman et al, 1994; Hughes, 1991) and other psychomotor stimulants (James and Rogers, 2005; Koelega, 1993). In this study, we tested the same smokers after overnight tobacco deprivation and during ad libitum smoking, which allowed an unequivocal determination that nicotine normalized deprivation-induced deficits and enhanced cognitive abilities in the nondeprived condition.

To our knowledge, this is the first study to demonstrate a dose-related enhancing effect of nicotine on computational abilities, which was characterized by increased task accuracy in both conditions and decreased response time in the nondeprived condition. Previous research reported that smoking or nicotine reversed deprivation-induced decrements in mental arithmetic or serial addition-subtraction tests (Landers et al, 1992; Pritchard, 1991) and 


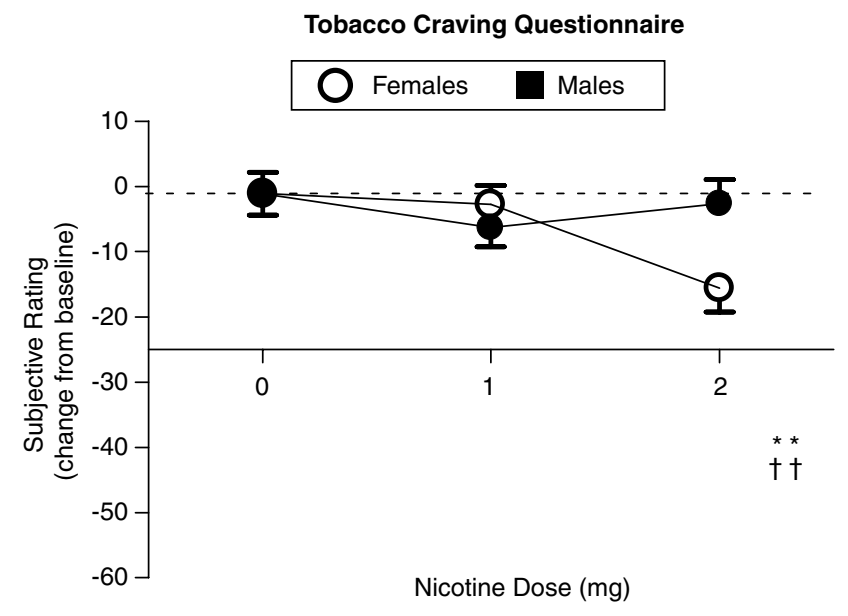

Figure 4 Effect of nicotine on total TCQ score. Each data point represents the mean $( \pm \mathrm{SE})$ change from baseline score of men $(n=14)$ or women $(n=14)$ averaged over tobacco-deprived and nondeprived conditions. Significant two-way (dose $\times$ sex) post hoc comparisons are as follows: $* * * 0.0$ I different from $0 \mathrm{mg}$ dose, ${ }^{\dagger \dagger} p<0.0$ I different from I mg dose.

improved performance in overnight tobacco-deprived smokers (Snyder and Henningfield, 1989). In the present study, we clearly showed that nicotine enhanced accuracy and response time on a task requiring simple mathematical skills in nondeprived smokers.

Studies have demonstrated that nicotine prevents or attenuates the vigilance decrement normally seen in prolonged sustained attention tasks (Heishman et al, 1994). Due to experimental constraints, we limited the CPT task to $6 \mathrm{~min}$, which was not sufficient time to observe a vigilance decrement. The performance improvement (fewer false alarms and faster response time) we observed when nicotine was administered after overnight tobacco deprivation is consistent with previous studies in which nicotine was administered transdermally (Bekker et al, 2005; Trimmel and Wittberger, 2004) or via subcutaneous injection (Foulds et al, 1996). In the nondeprived condition, we observed increased hits, decreased false alarms, and decreased variability of response time. Response time variability is considered an index of the consistency of focus during performance of an attentional task. To our knowledge, this is the first demonstration of a nicotineinduced facilitation of response time variability in nondeprived smokers, although a similar finding has been observed in nonsmokers (Levin et al, 1998) and patient populations (Levin et al, 1996; White and Levin, 1999).

Neuroimaging studies indicate that performance on continuous attention tasks is associated with activation in fronto-parieto-thalamic regions implicated in attention (Coull et al, 1996). Lawrence et al (2002) reported that nicotine-enhanced performance on a CPT correlated with increased activation in parietal and thalamic regions, suggesting that nicotine facilitated focusing of attentional resources (consistent with our finding of decreased response time variability). Thus, the ability of nicotine to enhance performance on tests of continuous attention, such as the CPT, appears to be related to its activation of frontal and parietal cortex and thalamus, brain areas known to
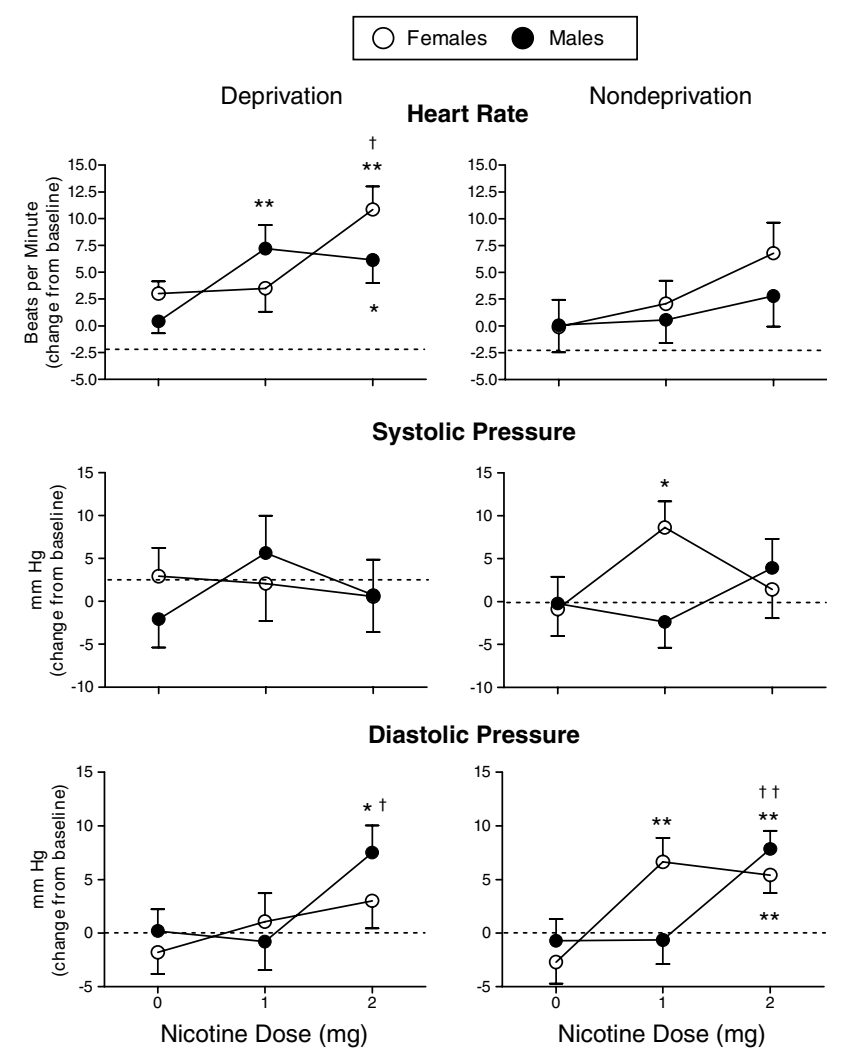

Figure 5 Effect of nicotine under conditions of tobacco deprivation and nondeprivation on heart rate (top row), systolic blood pressure (middle row), and diastolic blood pressure (bottom row). Each data point represents the mean $( \pm$ SE) change from baseline score of men $(n=14)$ or women $(n=14)$ at the 6 min postdose measurement. Significant fourway (dose $\times$ condition $\times$ se $\times \times$ time) post hoc comparisons are as follows: * $p<0.05$ different from $0 \mathrm{mg}$ dose, $* * * 0.01$ different from $0 \mathrm{mg}$ dose, ${ }^{\dagger} p<0.05$ different from I mg dose, ${ }^{\dagger \dagger} p<0.0$ I different from I mg dose.

contain significant densities of nicotinic cholinergic receptors (Fujita et al, 2003; Gallezot et al, 2005).

Nicotine had no effect on the N-back test in either the deprived or nondeprived condition. Although several studies have demonstrated that smoking or nicotine can improve working memory in tobacco-deprived or nondeprived smokers (Ernst et al, 2001; Grobe et al, 1998) and in nonsmokers (Kumari et al, 2003; McClernon et al, 2003), our results are in agreement with others who reported no nicotine-associated improvement in working memory (Kleykamp et al, 2005; Myers et al., 2004; Park et al, 2000).

Tobacco deprivation resulted in expected subjective effects, including increased ratings of urge to smoke, craving, and negative mood and a trend toward decreased relaxation and alertness. With respect to nicotine administration, women were more sensitive to the subjective effects of the active spray. This was particularly noticeable in the nondeprived session, during which women reported less urge to smoke, decreased negative mood and jitteriness, and, conversely, diminished positive mood, indicating generalized sensitivity to the drug. In contrast, the only significant nicotine effect men endorsed in the nondeprived session was feeling more stimulated. The TCQ data showed the same pattern; only women reported significantly less tobacco craving following nicotine administration across 


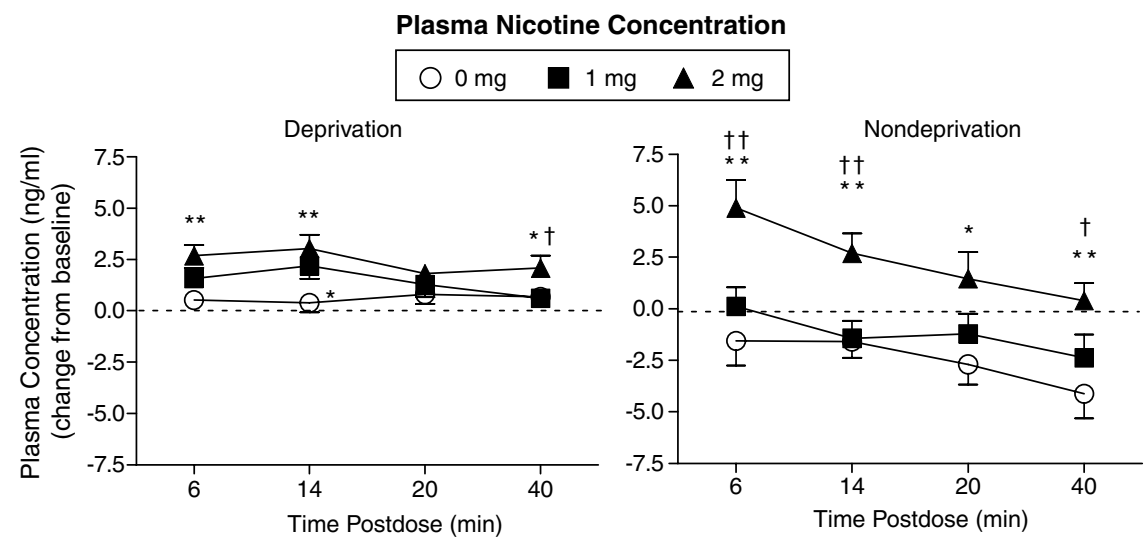

Figure 6 Time course of plasma nicotine concentration as a function of nicotine dose under conditions of tobacco deprivation and nondeprivation. Each data point represents the mean change from baseline score of men $(n=14)$ or women $(n=13)$. Significant three-way (dose $\times$ condition $\times$ time) post hoc comparisons are as follows: $* p<0.05$ different from $0 \mathrm{mg}$ dose, ${ }^{*} * \mathrm{p} p<0.0 \mathrm{I}$ different from $0 \mathrm{mg}$ dose, ${ }^{\dagger} p<0.05$ different from I mg dose, ${ }^{\dagger \dagger} p<0.0$ I different from I mg dose.

sessions. Similarly, Eissenberg et al (1999) found that, after smoking two cigarettes, women reported significantly less desire to smoke than men. Others also have noted sex differences in subjective response to nicotine. For example, File et al (2001) reported that women nonsmokers reported feeling less physically tired and men more tired after receiving $2 \mathrm{mg}$ intranasal nicotine. Eissenberg et al (1999) found that, after smoking, women reported significantly less restlessness, sedation, and difficulty concentrating than men. Women have reported more positive subjective responses to nicotine when it was administered by smoking compared with nasal spray (Perkins et al, 1994). In the present study, women reported more positive and negative responses to intranasal nicotine compared with men.

The placebo spray produced side effects (nose and throat irritation, watery eyes) that were very similar in magnitude and duration to the active spray, resulting in an effective placebo condition. One possibility for the greater subjective responsivity on the part of women in this study was that they were able to discriminate between active and placebo spray. However, ratings of drug liking did not differ as a function of dose, condition, and sex, suggesting that men and women were not able to discern active drug from placebo. The uniformly low ratings of drug liking are consistent with the minimal abuse liability of nicotine nasal spray (Schuh et al, 1997).

The primary clinical advantage of nicotine nasal spray over other nicotine replacement medications, such as gum and patch, is the relatively rapid absorption of nicotine to alleviate acute withdrawal symptoms (Henningfield, 1995). We observed mean $C_{\max }$ values of $4.8-13.6 \mathrm{ng} / \mathrm{ml}$ at 6-14 min postdose, which is consistent with other investigations of nicotine nasal spray preparations (Guthrie et al, 1999; Johansson et al, 1991; Sutherland et al, 1992). Guthrie et al (1999) found steady plasma nicotine concentration over $30 \mathrm{~min}$, which is consistent with our $2 \mathrm{mg}$ dose data in the tobacco-deprived condition (see Figure 6). Because we did not adjust dose for body weight, women likely received higher nicotine doses on a $\mathrm{mg} / \mathrm{kg}$ basis than men; however, we observed no sex differences in plasma nicotine concentration following intranasal nicotine, which is consistent with previous reports (Benowitz and Jacob, 1994).
We did, however, find that women had significantly lower baseline cotinine concentrations than men in the deprived and nondeprived conditions, which is explained by the finding that women metabolize nicotine and cotinine faster than men (Benowitz et al, 2006).

Nicotine nasal spray has been shown to affect cardiovascular measures, producing modest increases in heart rate and blood pressure within minutes after dosing, which decline over 30-60 min. Administration of $2 \mathrm{mg}$ nicotine to overnight-deprived smokers produced increases in heart rate of 15-22 beats per min, systolic blood pressure of $8-14 \mathrm{~mm} \mathrm{Hg}$, and diastolic blood pressure of $10-11 \mathrm{~mm} \mathrm{Hg}$ (Perkins et al, 1986; Sutherland et al, 1992). We observed slightly smaller increases in heart rate and blood pressure following the $2 \mathrm{mg}$ nicotine dose in the tobacco-deprived condition. Women showed blood pressure increases only in the nondeprived condition, whereas men evidenced increased diastolic pressure only after the $2 \mathrm{mg}$ dose in both conditions. In general, sex differences have not been observed in acute physiological responses to nicotine (Benowitz and Hatsukami, 1998; Perkins et al, 1999).

A potential limitation of this study involved the repeated within-session dosing, which might have resulted in carryover between nicotine administrations. Dose order was randomized using a Latin square design to control for carry-over effects, and plasma nicotine concentrations had declined to near-baseline levels within the $90 \mathrm{~min}$ interval between doses. If carry-over effects were a significant factor, then dose-response functions would have been attenuated; however, we observed orderly dose-related changes on many variables. This study builds on previous research in behavioral pharmacology using cumulative or repeated dosing paradigms to determine dose-response functions within single experimental sessions (Chait et al, 1988; Perkins et al, 1997).

The results of this and similar research are important for two clinically relevant reasons. As noted earlier, there is interest in pursuing nicotinic analogs as cognitive enhancing agents in various patient populations. Having empirical information about nicotine's ability or inability to enhance specific elements of cognition in normal smokers and nonsmokers will help guide development of novel 
therapeutic uses of nicotine in cognitively impaired populations. Second, understanding the conditions by which nicotine produces beneficial cognitive effects might enhance smoking cessation strategies. Knowing which aspects of attention and cognition are differentially affected by nicotine might direct more effective use of currently available medications or combinations thereof during quit attempts and might guide the development of novel medications for the treatment of tobacco dependence.

\section{ACKNOWLEDGEMENTS}

We thank Dr Kenneth Perkins for information on preparing the placebo nasal spray and John Etter for his excellent assistance in the conduct of the study.

\section{DISCLOSURE/CONFLICT OF INTEREST}

This research was supported by the Intramural Research Program of the NIH, National Institute on Drug Abuse. The authors declare there are no conflicting financial interests to disclose.

\section{REFERENCES}

American Psychiatric Association (2000). Diagnostic and Statistical Manual of Mental Disorders. American Psychiatric Association: Washington, DC.

Bancroft A, Levin ED (2000). Ventral hippocampal $\alpha 4 \beta 2$ nicotinic receptors and chronic nicotine effects on memory. Neuropharmacology 39: 2770-2778.

Bekker EM, Böcker KBE, Van Hunsel F, van den Berg MC, Kenemans JL (2005). Acute effects of nicotine on attention and response inhibition. Pharmacol Biochem Behav 82: 539-548.

Benowitz NL, Hatsukami DK (1998). Gender differences in the pharmacology of nicotine addiction. Addict Biol 3: 383-404.

Benowitz NL, Jacob P (1994). Meabolism of nicotine to cotinine studied by a dual stable isotope method. Clin Pharmacol Ther 56: 483-493.

Benowitz NL, Lessov-Schlaggar CN, Swan GE, Jacob P (2006). Female sex and oral contraceptive use accelerate nicotine metabolism. Clin Pharmacol Ther 79: 480-488.

Bizarro L, Patel S, Murtagh C, Stolerman IP (2004). Differential effects of psychomotor stimulants on attentional performance in rats: nicotine, amphetamine, caffeine and methylphenidate. Behav Pharmacol 15: 195-206.

Buccafusco JJ, Jackson WJ (1991). Beneficial effects of nicotine administered prior to a delayed matching-to-sample task in young and aged monkeys. Neurobiol Aging 12: 233-238.

Chait LD, Corwin RL, Johanson CE (1988). A cumulative dosing procedure for administering marijuana smoke to humans. Pharmacol Biochem Behav 29: 553-557.

Cohen JD, Forman SD, Braver TS, Casey BJ, Servan-Schreiber D, Noll DC (1994). Activation of the prefrontal cortex in a nonspatial working memory task with functional MRI. Hum Brain Mapp 1: 293-304.

Conners CK, Levin ED, Sparrow E, Hinton SC, Erhardt D, Meck WH et al (1996). Nicotine and attention in adult attention deficit hyperactivity disorder (ADHD). Psychopharmacol Bull 32: $67-73$.

Coull JT, Frith CD, Frackowiak RSJ, Grasby PM (1996). A frontoparietal network for rapid visual information processing: a PET study of sustained attention and working memory. Neuropsychologia 34: 1085-1095.
Eissenberg T, Adams C, Riggins EC, Likness M (1999). Smokers' sex and the effects of tobacco cigarettes: subject-rated and physiological measures. Nicotine Tob Res 1: 317-324.

Ernst M, Matochik JA, Heishman SJ, Van Horn JD, Jons PH, Henningfield JE et al (2001). Effect of nicotine on brain activation during performance of a working memory task. Proc Natl Acad Sci 98: 4728-4733.

Felix R, Levin ED (1997). Nicotinic antagonist administration into the ventral hippocampus and spatial working memory in rats. Neuroscience 81: 1009-1017.

File SE, Fluck E, Leahy A (2001). Nicotine has calming effects on stress-induced mood changes in females, but enhances aggressive mood in males. Int J Neuropsychopharmacol 4: 371-376.

Foulds J, Stapleton J, Swettenham J, Bell N, McSorley K, Russell MAH (1996). Cognitive performance effects of subcutaneous nicotine in smokers and never-smokers. Psychopharmacology 127: 31-38.

Fujita M, Ichise M, van Dyck CH, Zoghbi SS, Tamagnan G, Mukhin AG et al (2003). Quantification of nicotinic acetylcholine receptors in human brain using [123I]5-I-A-85380 SPET. Eur J Nucl Med Mol Imaging 30: 1620-1629.

Gallezot JD, Bottlaender M, Gregoire MC, Roumenov D, Deverre JR, Coulon C et al (2005). In vivo imaging of human cerebral nicotinic acetylcholine receptors with $2-18$ F-fluoro-A-85380 and PET. J Nucl Med 46: 240-247.

Grobe JE, Perkins KA, Goettler-Good J, Wilson A (1998). Importance of environmental distractors in the effects of nicotine on short-term memory. Exp Clin Psychopharmacol 6: 209-216.

Grottick AJ, Higgins GA (2000). Effect of subtype selective nicotinic compounds on attention as assessed by the five-choice serial reaction time task. Behav Brain Res 117: 197-208.

Guthrie SK, Zubieta J-K, Ohl L, Ni L, Koeppe RA, Minoshima S et al (1999). Arterial/venous plasma nicotine concentrations following nicotine nasal spray. Eur J Clin Pharmacol 55: 639-643.

Heatherton TF, Kozlowski LT, Frecker RC, Fagerström KO (1991). The Fagerström test for nicotine dependence: a revision of the Fagerström Tolerance Questionnaire. Br J Addict 86: 1119-1127.

Heishman SJ (1998). What aspects of human performance are truly enhanced by nicotine? Addiction 93: 317-320.

Heishman SJ, Henningfield JE (2000). Tolerance to repeated nicotine administration on performance, subjective, and physiological responses in nonsmokers. Psychopharmacology 152: 321-333.

Heishman SJ, Singleton EG, Crouch DJ (1996). Laboratory validation study of Drug Evaluation and Classification program: ethanol, cocaine, and marijuana. J Anal Toxicol 20: 468-483.

Heishman SJ, Singleton EG, Moolchan ET (2003). Tobacco craving questionnaire: reliability and validity of a new multi-factorial instrument. Nicotine Tob Res 5: 645-654.

Heishman SJ, Snyder FR, Henningfield JE (1993). Performance, subjective, and physiological effects of nicotine in nonsmokers. Drug Alcohol Depend 34: 11-18.

Heishman SJ, Taylor RC, Henningfield JE (1994). Nicotine and smoking: a review of effects on human performance. Exp Clin Psychopharmacol 2: 345-395.

Henningfield JE (1995). Nicotine medications for smoking cessation. N Engl J Med 333: 1196-1203.

Hughes JR (1991). Distinguishing withdrawal relief and direct effect of smoking. Psychopharmacology 104: 409-410.

James JE, Rogers PJ (2005). Effects of caffeine on performance and mood: withdrawal reversal is the most plausible explanation. Psychopharmacology 182: 1-8.

Johansson C-J, Olsson P, Bende M, Carlsson T, Gunnarsson PO (1991). Absolute bioavailability of nicotine applied to different nasal regions. Eur J Clin Pharmacol 41: 585-588.

Kelton MC, Kahn HJ, Conrath CL, Newhouse PA (2000). The effects of nicotine on Parkinson's disease. Brain Cogn 43: 274-282. 
Kleykamp BA, Jennings JM, Blank MD, Eissenberg TE (2005). The effects of nicotine on attention and working memory in never-smokers. Psychol Addict Beh 19: 433-438.

Koelega HS (1993). Stimulant drugs and vigilance: a review. Psychopharmacology 111: 1-16.

Kumari V, Gray JA, ffytche DH, Mitterschiffthaler MT, Das M, Zachariah E et al (2003). Cognitive effects of nicotine in humans: an fMRI study. NeuroImage 19: 1002-1013.

Landers DM, Crews DJ, Boutcher SH, Skinner JS, Gustafsen S (1992). The effects of smokeless tobacco on performance and psychophysiological response. Med Sci Sports Exercise 24: 895-903.

Lawrence NS, Ross TJ, Stein EA (2002). Cognitive mechanisms of nicotine on visual attention. Neuron 36: 539-548.

Levin ED, Bettegowda C, Blosser J, Gordon J (1999). AR-R17779, an alpha7 nicotinic agonist, improves learning and memory in rats. Behav Pharmacol 10: 675-680.

Levin ED, Christopher NC (2002). Persistence of nicotinic agonist RJR 2403 induced working memory improvement in rats. Drug Dev Res 55: 97-103.

Levin ED, Conners CK, Silva D, Hinton SC, Meck WH, March J et al (1998). Transdermal nicotine effects on attention. Psychopharmacology 140: 135-141.

Levin ED, Kaplan S, Boardman A (1997). Acute nicotine interactions with nicotinic and muscarinic antagonists: working and reference memory effects in the 16 -arm radial maze. Behav Pharmacol 8: 236-242.

Levin ED, McClernon FJ, Rezvani AH (2006). Nicotinic effects on cognitive function: behavioral characterization, pharmacological specification, and anatomic localization. Psychopharmacology 184: 523-539.

Levin ED, Wilson W, Rose JE, McEvoy J (1996). Nicotinehaloperidol interactions and cognitive performance in schizophrenics. Neuropsychopharmacology 15: 429-436.

McClernon FJ, Gilbert DG, Radtke R (2003). Effects of transdermal nicotine on lateralized identification and memory interference. Hum Psychopharmacol Clin Exp 18: 339-343.

Min SK, Moon IW, Ko RW, Shin HS (2001). Effects of transdermal nicotine on attention and memory in healthy elderly nonsmokers. Psychopharmacology 159: 83-88.

Myers CS, Robles O, Kakoyannis AN, Sherr JD, Avila MT, Blaxton TA et al (2004). Nicotine improves delayed recognition in schizophrenic patients. Psychopharmacology 174: 334-340.

National Cancer Institute (2003). Those Who Continue to Smoke: Is Achieving Abstinence Harder and Do We Need to Change our Interventions?. US Department of Health and Human Services: Bethesda, MD.

Park S, Knopick C, McGurk S, Meltzer HY (2000). Nicotine impairs spatial working memory while leaving spatial attention intact. Neuropsychopharmacology 22: 200-209.
Perkins KA, DiMarco A, Grobe JE, Scierka A, Stiller RL (1994). Nicotine discrimination in male and female smokers. Psychopharmacology 116: 407-413.

Perkins KA, Donny E, Caggiula AR (1999). Sex differences in nicotine effects and self-administration: review of human and animal evidence. Nicotine Tob Res 1: 301-315.

Perkins KA, Epstein LH, Stiller R, Jennings JR, Christiansen C, McCarthy T (1986). An aerosol spray alternative to cigarette smoking in the study of the behavioral and physiological effects of nicotine. Behav Res Methods Instrum Comput 18: 420-426.

Perkins KA, Sanders M, D'Amico D, Wilson A (1997). Nicotine discrimination and self-administration in humans as a function of smoking status. Psychopharmacology 131: 361-370.

Pritchard WS (1991). Electroencephalographic effects of cigarette smoking. Psychopharmacology 104: 485-490.

Rezvani AH, Caldwell DP, Levin ED (2004). Nicotine-antipsychotic drug interactions and attentional performance. Eur J Pharmacol 486: $175-182$.

Schuh KJ, Schuh LM, Henningfield JE, Stitzer ML (1997). Nicotine nasal spray and vapor inhaler: abuse liability assessment. Psychopharmacology 130: 352-361.

Seidl R, Tiefenthaler M, Hauser E, Lubec G (2000). Effects of transdermal nicotine on cognitive performance in Down's syndrome. Lancet 356: 1409-1410.

Sherwood N (1993). Effects of nicotine on human psychomotor performance. Hum Psychopharmacol Exp Clin 8: 155-184.

Shipley WC (1946). Institute of Living Scale. Western Psychological Services: Los Angeles.

Snyder FR, Henningfield JE (1989). Effects of nicotine administration following $12 \mathrm{~h}$ of tobacco deprivation: assessment on computerized performance tasks. Psychopharmacology 97: 17-22.

Socci DJ, Sanberg PR, Arendash GW (1995). Nicotine enhances Morris water maze performance of young and aged rats. Neurobiol Aging 16: 857-860.

Sutherland G, Russell MAH, Stapleton J, Feyerabend C, Ferno O (1992). Nasal nicotine spray: a rapid nicotine delivery system. Psychopharmacology 108: 512-518.

Trimmel M, Wittberger S (2004). Effects of transdermally administered nicotine on aspects of attention, task load, and mood in women and men. Pharmacol Biochem Behav 78: 639-645.

Van Kampen M, Selbach K, Schneider R, Schiegel E, Boess F, Schreiber R (2004). AR-R17779 improves social recognition in rats by activation of nicotinic alpha7 receptors. Psychopharmacology 172: 375-383.

White HK, Levin ED (1999). Four-week nicotine skin patch treatment effects on cognitive performance in Alzheimer's disease. Psychopharmacology 143: 158-165.

Wonnacott S (1997). Presynaptic nicotinic Ach receptors. Trends Neurosci 20: 92-98. 